\title{
Experimental Evaluation of Airlift Performance for Vertical Pumping of Water in Underground Mines
}

\author{
Parviz Enany $^{1}$ (1) $\cdot$ Oleksandr Shevchenko $^{1} \cdot$ Carsten Drebenstedt $^{1}$
}

Received: 10 September 2020 / Accepted: 28 July 2021 / Published online: 14 August 2021

(c) The Author(s) 2021

\begin{abstract}
This paper presents experimental studies on the optimization of air-water flow in an airlift pump. Airlift pumps use compressed gas to verticall transport liquids and slurries. Due to the lack of theoretical equations for designing and predicting flow regimes, experimental investigations must be carried out to find the best condition to operate an airlift pump at high efficiency. We used a new air injection system and different submergence ratios to evaluate the output of a simple pump for vertical displacement of water in an underground mine. The tests were carried out in a new device with $5.64 \mathrm{~m}$ height and $10.2 \mathrm{~cm}$ circular riser pipe. Three air-jacket pipes, at different gas flows in the range of $0.002-0.09 \mathrm{~m}^{3} / \mathrm{s}$ were investigated with eight submergence ratios. It was found that with the same air flow rate, the most efficient flow of water was achieved when an air jacket with $3 \mathrm{~mm}$ diameter holes was used with a submergence ratio between 0.6 and 0.75 . In addition, a comparison of practical results with two theoretical models proposed by other investigators showed that neither was able to accurately predict airlift performance in air-water flow mode.
\end{abstract}

Keywords Drainage $\cdot$ Air-water two-phase flow $\cdot$ Efficiency $\cdot$ Submergence ratio

\section{Introduction}

An airlift pump is a device for transporting slurries and liquids using compressed gas injection. More than a two hundred years ago, Carl Luster introduced the concept of the first airlift pump in Germany (Ahmed et al. 2016). The pump consists of a vertical riser pipe and an air injector; the injector is often installed at or near the bottom of the riser pipe. The action of the pump is based on changing the density of the liquid inside the riser pipe by injecting compressed air (Abed et al. 2018). Then the drag force between the formed air bubbles and the water helps the liquid phase to move upwards (Pougatch and Salcudean 2008). The most common examples reported in the literature for using this pump are sewage treatment plants (Kalenik 2015), raising liquid hydrocarbons in the oil industry (Clark and Dabolt 1986), shaft and well drilling (Maliky 2014), and mining of minerals from the ocean (Khalil et al. 1999).

Parviz Enany

parviz.enany@student.tu-freiberg.de

1 Faculty of Mining and Special Civil Engineering, Technische Universität Bergakademie Freiberg, Gustav-Zeuner Straße 1A, 09599 Freiberg, Germany
This type of pump is especially appropriate for situations where other pumping methods face technical problems such as: when the water is corrosive (due to the high cost of repairs for conventional pumps), where it is not possible to filter water and the ability to simultaneous transfer sediment and water vertically is required, where pre-treatment of water by blowing in some useful gas is needed, such as for mitigation of acid mine drainage (AMD), and for pumping sparkling water, especially if the percentage of gas in the water exceeds 14\% (Awari et al. 2004).

Despite the simple structure of the airlift system, there is no proper theoretical model for designing the different parts of it (Ligus et al. 2019; Samaras et al. 2005) because the details of the flow characteristics have not yet been accurately determined. Hence, creating optimal economic conditions for the operational performance of the airlift pump based on the latest theoretical research is difficult, due to the method's broad diversity and varied dimensions.

Many researchers (Cacharda and Delhaye 1996; Clark and Dabolt 1986; Lockhart and Martinelli 1949; Nicklin 1963; Stenning and Martin 1968) have tried to offer possible formulae based on a variety of theories such as first law of thermodynamics, adiabatic air-water flow, two phase slug flow, and one-dimensional flow. Unfortunately, 
the formulae have not yet achieved significant success in predicting the performance of this device under different conditions. As an example, Jeelani et al. (1979) showed that the theoretical equations presented by Hussain and Spedding (1976) are not applicable to riser pipes with diameters larger than $8 \mathrm{~mm}$.

In addition, for convenience in calculations and easier expression, some researchers have ignored parameters in their theoretical equations, which reduced the precision of their formulae. Nicklin (1963) presented a theoretical formulation for the performance of an airlift with air-water flow but neglected the entrance effects of air and water in the riser pipe and assumed that air-water flow in the riser tube was in slug form. Sharma and Sachdeva (1976) showed that increasing the inlet air velocity caused the flow of air bubbles inside the riser tube to change from bubbly to slug flow. This process can continue to occur up to a point where the air-water flow changes to annular flow, which greatly reduces vertical water displacement.

The use of photographic techniques showed that there were actually four different types of air-water flow regimes in the riser tube (Francois et al. 1996; Taitel et al. 1997), depending on the amount of influent air. Therefore, theoretical equations obtained based on only one of the flow regimes can certainly not predict the overall performance of the pump in different conditions.

Researchers have tested different ideas to improve the pumping range and efficiency of this device. These experiments led to the discovery of which factors can most affect the performance of an airlift, and so these should be incorporated into the theoretical equations. Among them, the most important parameters are gas bubble dimension, the changing density and momentum of the air-water mixture in the air jacket (a perforated tube for radial air injection into a riser tube), the friction of air with the inner tube wall, and the temperature of water. The latter has less effect than the others (Oueslati et al. 2017).

The role of gas bubbles can be examined from various aspects but principally the aspects fall into two groups: smaller bubble size and delay of bubble agglomeration. Parker (1980) investigated the effect of two models of air injectors in air-water flow. He found that a combination of high air flow rates with small holes in the footpiece (a perforated disk at the base inlet of the riser pipe for axial air injection) improved the capability of vertical water transportation with airlift. Awari et al. (2004) showed that increasing the diameter of a tapered riser tube delayed air bubble accumulation and improved the efficiency of water pumping from great depths.

To reduce the friction of flow with the inner riser tube wall, Ahmed and his colleagues (2016) designed a novel type of air jacket that could inject compressed air radially and axially close to the riser tube wall. In 1979, Khalil and
Elshorbagy also reduced the friction coefficient by designing a new riser tube that raised the efficiency of the pump in air-water flow. In addition, to decrease the friction and lower pressure loss in the pipe, a drag reduction agent was introduced to aid the air-water flow. This component loses efficiency over time by mechanical and thermal effects. Therefore, surfactant can be used to overcome this problem and also lower surface tension. Based on the four types of air-water flow regimes, the positive effect of this flow improvement has been reported in different ranges, sometimes reaching up to $80 \%$ (Liu et al. 2014).

Oueslati and Megriche (2017) investigated the effect of water temperature on the performance of an airlift pump. They increased the water temperature up to $70{ }^{\circ} \mathrm{C}$ and at each step it became clear that the pump efficiency increased slightly as the water temperature increased. Since the process of compressing the air increases the temperature of the injected air, it is sometimes necessary to pay attention to the temperature of the air-water mixture to obtain proper performance.

Despite the various researchers that have investigated airlift pumping, there was no adequate study of the outcomes of using this device for mine dewatering. One report by Shaw (1920) describes its use in an underground mine in Mexico but unfortunately, there are insufficient details about the device and its operation (Clark 1986; Francois 1996). In this paper, we provide the results of a practical experiment, focused on improving airlift performance by air bubble control with three different air jackets. Our main objective was to evaluate the conditions of using an airlift for drainage systems in underground mines. Therefore, air-water flow experiments were performed to study the efficient operation of airlift pumping by air injection with eight submergence ratios (the ratio between the immersed length of the riser and its total length) at different air flow rates.

\section{Experimental Data}

The airlift pump was designed at the Technical University Bergakademie Freiberg, with support from the HydroCoal Plus project, funded by the Research Fund for Coal and Steel (European Commission). The pump was installed in the Reiche Zeche experimental mine (Freiberg, Germany) at a depth of $100 \mathrm{~m}$. The tests were carried out in ambient conditions at a temperature of $17.0^{\circ} \mathrm{C}$ and static pressure of $97.8 \mathrm{kPa}$.

A model airlift pump is illustrated in Fig. 1. The riser pipe (3) is a transparent tube with internal diameter $10.2 \mathrm{~cm}$ and outside diameter $11 \mathrm{~cm}$. The total length of the riser, which is calculated without considering the length of the suction pipe and the air jacket, is $4.26 \mathrm{~m}$. To save water consumption and the possibility of testing the pump at submergence ratios 
close to one, the airlift is designed to work in closed cycle. That is why the upper part of the riser pipe is connected to one separator tank (5), where the air can be easily separated from the pumped air and water mixture. In addition, the water storage pipe (downcomer) (6) is a steel cylinder with an inner diameter of $41 \mathrm{~cm}$ is used to prevent static water level fluctuations.

A rotary screw compressor (Kaeser CS121) was used to supply the compressed air required by the airlift. The compressor has a power of $75 \mathrm{Kw}$ and produced $11.6 \mathrm{~m}^{3} / \mathrm{min}$ of compressed air at a maximum pressure of 8 bar. To prevent air pressure fluctuations during the test, compressed air was first stored in the reservoir and then travelled through a 38.9 $\mathrm{mm}$ diameter pipeline to an on/off valve, then to a distributor, where the air is divided into four injection pipes to the air jacket. These four air-supply lines cause the air to be evenly distributed around the air jacket to balance the radial momentum of the air from each side. The air jacket is a cylindrical stainless-steel pipe with circular holes of varying numbers and diameters uniformly distributed around it. Supplemental Figure S-1 shows the schematic structure of the tested air jacket. To equalize the conditions of each injector, the total area of the holes on each injector was chosen equal to $5.9 \times 10^{-4} \mathrm{~m}^{2}$ (details are given in Table 1).

To measure air velocity and pressure, two sensors were installed before the on/off valve: a flow sensor (IFM SA5004) with a measuring range of 2 to $100 \mathrm{~m} / \mathrm{s}$ and an accuracy of $\pm 7 \%$ measured value $+2 \%$ of the final value of the measuring range, and a pressure transmitter (IFM PN3093) with a measuring range from 0 to 25 bar with an uncertainty of less than $\pm 0.5 \%$. The water flow was measured with a magnetic inductor device from Optiflux with a precision of $\approx 0.5 \%$ where it was installed below the air jacket. The air and water temperatures were also measured during the tests. At the beginning of the experiment, the air temperature was constant and its value diminished with time during the pumping from $15^{\circ} \mathrm{C}$ to $12{ }^{\circ} \mathrm{C}$. Eight submergence ratios were used to cover the entire experimental range: 0.31 , $0.4,0.5,0.6,0.7,0.75,0.8$, and 0.89 ; this was controlled by the drainage valve (1) where it connected to the water storage pipe (6) - the numbers refer to locations on Fig. 1. As the air-water mixture began to go up the riser tube, a barometer (7) showed a slight decrease in the static water level. This drop, just like that reported by Maliky (2014), was very small and did not affect the results. To induce circulation of the liquid in the riser pipe, the minimum air velocity was varied at each submergence ratio and measurements began after the airlift operation stabilized. For each intended submergence ratio, the test was performed four times with $5 \mathrm{~min}$ intervals between repeated tests within a measuring series. The software collected data at a frequency of two $\mathrm{Hz}$ for $500 \mathrm{~s}$.

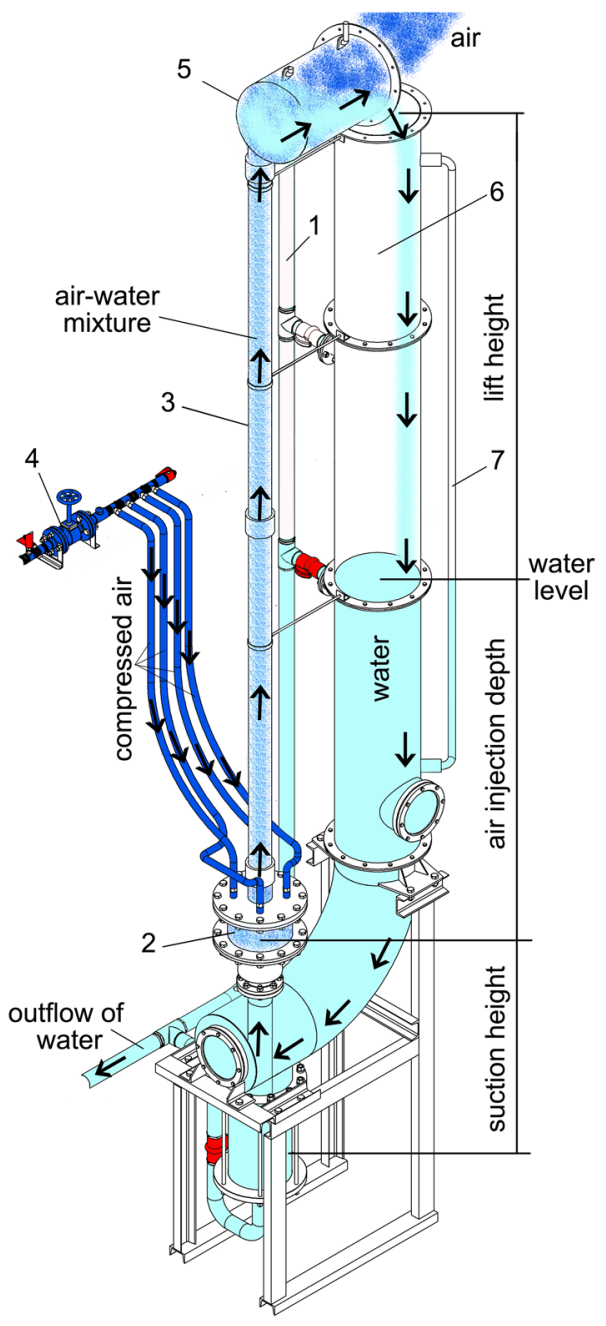

Fig. 1 Schematic of working principle of the airlift pump

Table 1 Parameters of investigated air-jacket

\begin{tabular}{lll}
\hline Type of air-jacket & Diameter of holes d $(\mathrm{mm})$ & $\begin{array}{l}\text { Number } \\
\text { of holes }\end{array}$ \\
\hline $\mathrm{P}_{1}$ & 3 & 84 \\
$\mathrm{P}_{2}$ & 6 & 21 \\
$\mathrm{P}_{3}$ & 9 & 9 \\
\hline
\end{tabular}

\section{Results and Discussion}

The experiment was done with three variable parameters: submergence ratio $\alpha$, air flow rate $\mathrm{Q}_{\mathrm{a}}$, and type of air jacket $\left(\mathrm{P}_{1}, \mathrm{P}_{2}\right.$, and $\left.\mathrm{P}_{3}\right)$. The main objective of this experiment was to find out the optimal airlift pump configuration for air-water mixture for use in draining an underground mine.

The effect of the compressed air on the air jacket has been described in detail previously (Ahmed et al. 2016; Kalenik 
2015; Khalil et al. 1999; Neto et al. 2008; Parker 1980). In this experiment, compressed air was blown parallel to the outer wall of the air jacket and did not hit it directly. This method avoids reducing the initial energy of the compressed air, allows the use all of the holes embedded in the air jacket, and creates an even entry of air into the riser pipe. Our experiment was designed to properly evaluate this new method of parallel air injection and to confirm the influential parameters identified by previous researchers, such as submergence ratio and air flow rate.

Each experiment started at the minimum air velocity required to initiate water circulation in the airlift. In terms of air consumption, the first type of air jacket with the smallest diameter hole required the least amount of air to raise the water to a height of $1 \mathrm{~m}$ (see supplemental Table S-1). In each air jacket, if the amount of injected air was less than the minimum, the gas bubbles could not provide the buoyant force required to move water upwards to pass through the water column and toward the separator tank (5).

Especially for submergence ratios less than 0.6 and low air flow rates, water flow fluctuations were visible in the riser pipe. Therefore, the mixture of water and air moved upwards irregularly. The flow fluctuation was such that the mixture of water and air fell slightly in the opposite direction of the main flow and continued to move vertically when the next high-pressure flow arrived. This phenomenon is considered an obstacle to the proper operation of the pump in the case of air-water flow. The water can move upwards more regularly (less flow fluctuations) if the amount of incoming air or the submergence ratio is increased. It is worth noting that a small amount of the flow irregularity in low submergence ratio pumping is due to water falling from the separator tank into the water storage pipe. This influence of a submergence ratio less than 0.6 can be seen clearly by the difference between the static pressure level and dynamic pressure in the barometer (7), which was installed along the outside of water storage pipe (downcomer).

Water flow fluctuations in the riser pipe also depends on hole dimensions in the air jacket. Compared to the other air jackets, type $\mathrm{P}_{1}$ produced very small air bubbles in the entire cross-section of the riser pipe, which decreased the amount of oscillation, caused the upward flow to be more regular form, and improved the pump's effectiveness. A similar phenomenon was also reported by Kalenik (2015).

As previously mentioned, the performance of the pump depends on the flow rate and pressure of the incoming air, the submergence ratio, and the friction of the fluid with the pipe wall. Due to the similarity of the friction in all of the experiments, this factor did not play an important role in this research, so the arithmetic average values measured for the other effective parameters were used.

The effect of incoming air on the velocity of the transported water for different submergence ratios is presented in Fig. 2 for mixer $P_{1}$. The starting point of each graph corresponds to the amount of air required for vertical water transfer up to $1 \mathrm{~m}$ from static level. Due to the short distance between the water in the riser pipe to the separator tank, this rule did not apply to submergence ratios of 0.8 and 0.89 . Therefore, the beginning of water circulation in the airlift was considered the starting point of the graph for those two submergence ratios.

Figure 2 reveals the effect of air flow and submergence ratio on water flow rate in air jacket $P_{1}$. For submergence ratios exceeding 0.5 , the water flow increased with a steeper slope, and after reaching the maximum, the effect of further air injection was insignificant. Figure 2 shows that for the same amount of air, the water flow was largest at a submergence ratio of 0.89 . One explanation for this is that the travel distance for an air bubble increases as the submergence ratio increases. Hence, air bubbles have enough time to transfer their energy to the water molecules, causing increased water flow. The velocity of compressed air did not show the same trend as the water transfer rate. For submergence ratios less than $\alpha=0.5$, much more air is required, e.g. $0.02 \mathrm{~m}^{3} / \mathrm{s}$ for $\alpha=0.3$, to initiate the transfer of water up the pipe. At higher submergence ratios, the water reaches considerable flow rates, even with just a small amount of compressed air.

In a study on a $4 \mathrm{~m}$ high airlift and three different types of air injectors, Kalenik (2015) concluded that the air flow and air pressure contributed more than $95 \%$ to the water pump flow, with all other factors contributing only $5 \%$. If we consider the best results of the present practical experiment (Fig. 2), it can be seen that increasing the air velocity up to $0.03 \mathrm{~m}^{3} / \mathrm{s}$ at a submergence ratio of 0.89 enhanced the displaced water by up to $67 \%$, while the same air flow and a submergence ratio of $\alpha=0.6$ increased the ultimate yield by $40 \%$. Therefore, Kalenik (2015) ignored the effect of other parameters such as submergence ratio. Raising the air velocity will be important whenever we can transfer the energy of the compressed air to the water in an optimal way, but will not always be the most effective in improving water pumping.

As can be seen from Fig. 3(1), increasing the volume of influent air kept increasing the water flow rate until it reached a maximum value. After the peak water flow was reached, increasing the influent air no longer affected the water flow rate. Instead, the flow rate was fairly constant and even show eventual slight reductions.

Relative to the mass flow of water created by a given injected air mass flow, with a submergence ratio of 0.89 , all of the experimental data for each air jacket tended to produce similar flow rates, as can be seen from the three curves in Fig. 3(1), especially for low values of air flow (less than 0.012). Similar conditions are observed for the submergence ratio of 0.31 in Fig. 3(2). In general, the flow of water increases slightly for air jacket holes when the submergence 
Fig. 2 Comparison of water flow rates with different submergence ratio for air-jacket $\mathrm{P}_{1}$

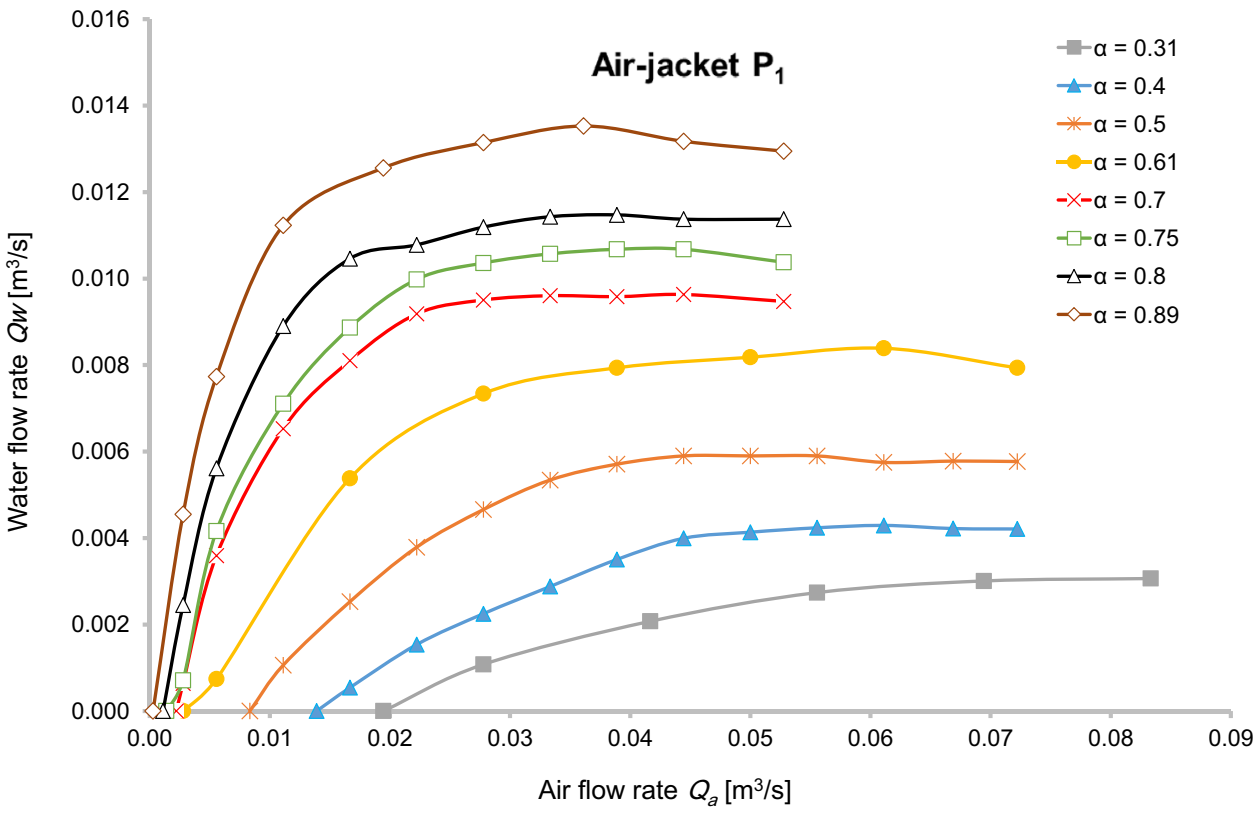

ratio is constant. Parker (1980), in his research on a small airlift with radial air injection conditions, found that the performance of the device was not affected by the number and diameter of holes in the air jacket. Parker's result cannot be generalized to all devices since Parker considered only one submergence ratio $(\alpha=0.55)$. It can be inferred from Fig. 3(1, 2), under certain conditions of air flow and submergence ratio, that air jacket $\mathrm{P}_{1}$, with smaller and more drilled holes, had a greater effect on the pumping efficiency compared to the other mixers, as long as the compressed air was injected parallel into the manifold.

\section{Comparison with the Theoretical Formulas}

Here we compare the results of our applied research with the two analytical studies presented by Stenning and Martin (1968) and Hussain and Spedding (1976) to predict the discharge of water. The Stenning and Martin equation was obtained by a combination of theoretical and practical research and assuming one-dimensional flow in the airlift and establishing momentum continuity between the inlet and outlet of a lifting tube. Due to the lack of sufficient explanation to use this formula, researchers have been proposed different methods. As inferred from Parker (1980), with an initial guess for $\mathrm{S}$ (slip ratio) and $\mathrm{K}$ (friction factor), the results of calculations should be plotted as two dimensionless parameters $\frac{V}{\sqrt{2 g L}}$ and $\frac{Q_{g}}{Q_{f}}$, where $\mathrm{V}$ is the velocity of the water in the entrance of the suction pipe, $g$ is gravitational acceleration, $\mathrm{L}$ is the length of the riser pipe, $\mathrm{Q}_{\mathrm{g}}$ is the air flow rate, and $\mathrm{Q}_{\mathrm{f}}$ is the water flow rate.
Meanwhile, Kassab et al. (2009) suggested an iterative procedure. First, we have to assume a value for the water flow rate and use it to calculate parameters $\mathrm{S}$ and $\mathrm{K}$. Then the value obtained from the calculations for the water flow rate should be compared with the initial guess; if the difference is less than 0.001 , then the calculations should be stopped, otherwise the steps should be started again from the beginning. Both procedures were tested to calculate the outflow of water, but the final results of calculations were clearly different. Since our experiments were performed on an airlift with a riser tube diameter of $10.2 \mathrm{~cm}$, Stenning and Martin also provided a prediction of performance for an airlift with a same diameter. The only difference was the length of riser pipe, which was about $6.5 \mathrm{~m}$ longer than our device. The results of that prediction are plotted against our experimental data for a submergence ratio of 0.75 in Fig. 4, which shows that Stenning \& Martin's methods underestimated the amount of air required to start the vertical water transfer. This inference is due to the fact that Weber (1974) in his research on pipes with different lengths and same diameter showed that, as the length of riser pipe increased, more air was needed to achieve the same water flow rate than when the pipe was shorter. Therefore, the starting point of the graph should be located further right of our test data. Parker (1980) also confirmed that the Stenning and Martin model did not accurately predict water flow at low air flow.

The results of water flow estimation by Hussain \& Spedding's formula are also displayed in Fig. 4. It is quite clear that their model overpredicts the amount of water flow. In particular, when the inlet air flow was low, the difference between the calculated values and experimental data was up to four-fold. However, as the amount of incoming air 
Fig. 3 Comparison of water flow rate with different airjackets for $\alpha=0.31$ and 0.89
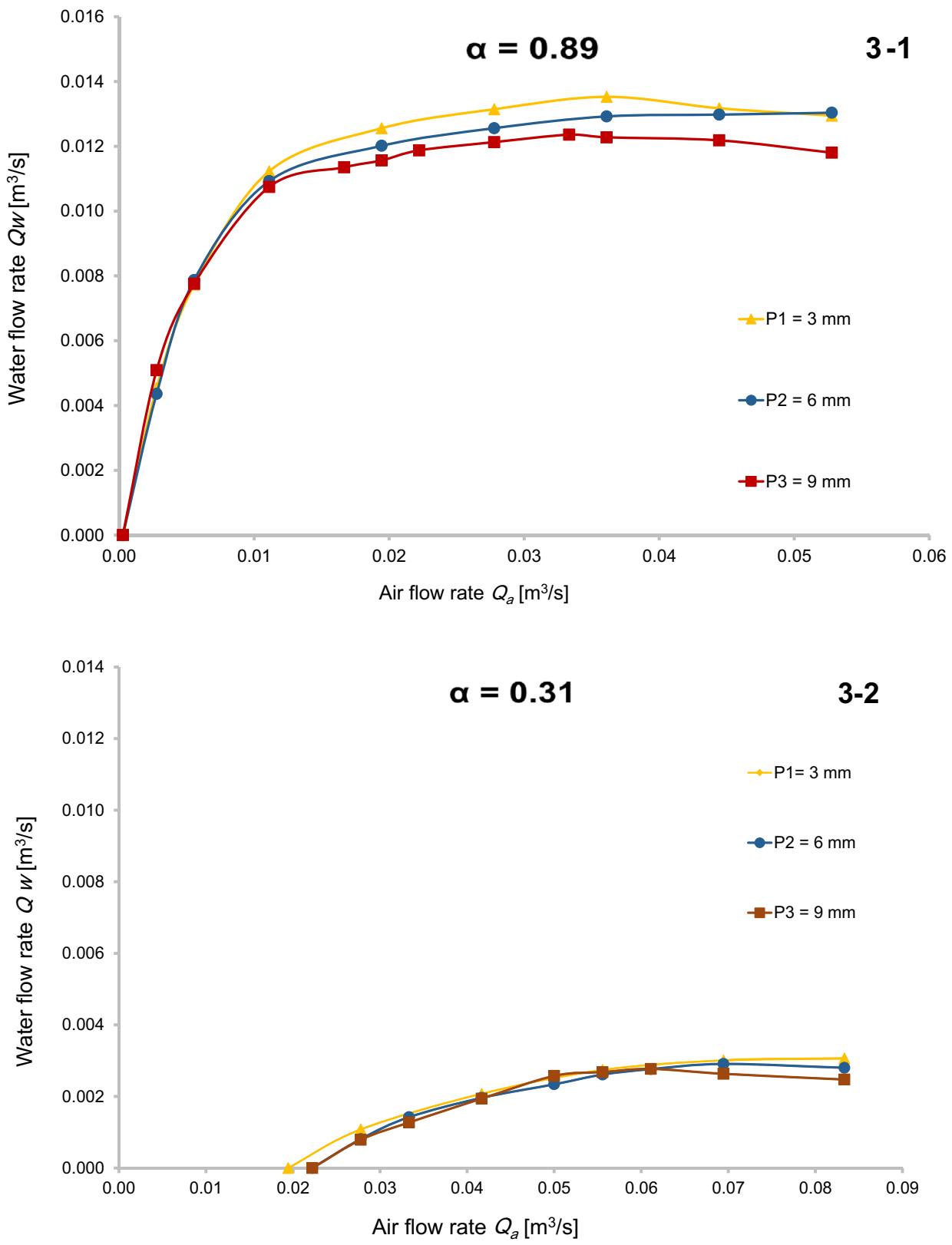

increases, the difference in results decreases. In Hussain and Spedding's model, the water flow rate goes to maximum quicker than our experimental data as well as the model from Stenning and Martin. Then the water flow suddenly starts to decrease, which is contrary to the usual patterns. Sawiski et al. (1999) also compared Hussain and Spedding's formula for a small-scale airlift, but he did not find any similarities between theory and experiment. Altogether, Hussain and Spedding's model is not capable to predicting the full range of water flow for an airlift. The source of this error can be found in two empirical coefficients $\mathrm{K}_{1}$ and $\mathrm{K}_{2}$, which they estimated from numerical comparisons with other experimental results.

\section{Efficiency}

For each experiment, the theoretical efficiency of the airlift pump can be calculated using the following equation (Reinemann et al. 1990):

$\eta=\frac{N_{2}}{N_{1}}$

This ratio is defined as an energy $\left(\mathrm{N}_{2}\right)$ required to pump the pure water to the separator tank, compared to the energy $\left(\mathrm{N}_{1}\right)$ used by the compressor to achieve isothermal compression of the air from atmospheric pressure to the air injection 
Fig. 4 Comparisons between the theoretical model and experimental results

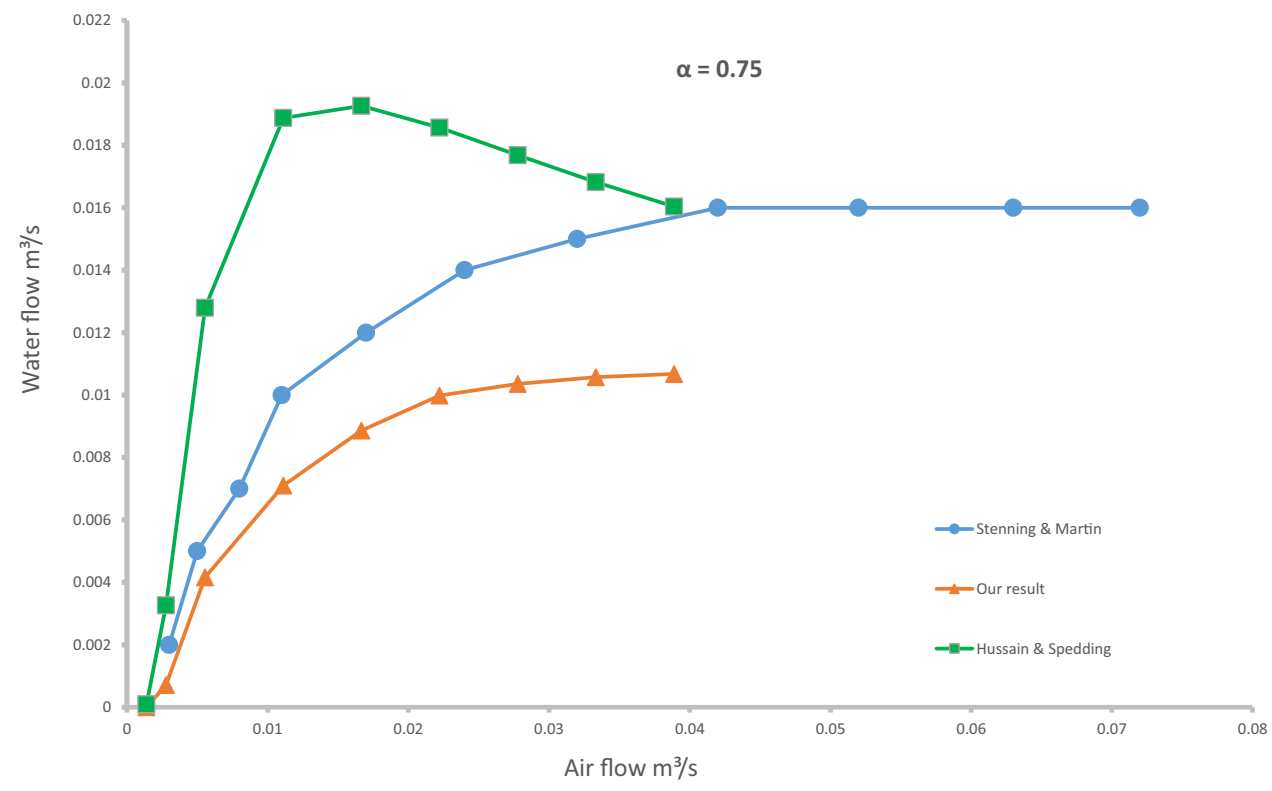

pressure. The results of this calculation are plotted for mixer $\mathrm{P}_{1}$ in Fig. 5.

In Fig. 5, it is apparent that for submergence ratios greater than 0.6 , a similar efficiency can be achieved for low airflow values and that the highest efficiency was associated with injecting compressed air at less than $0.01 \mathrm{~m}^{3} / \mathrm{s}$. Figure 5 clearly shows that the economic performance of the airlift is strongly dependent on the submergence ratio. For a submergence ratio less than 0.6 , the efficiency obtained from pumping water is, at best, $\approx 20 \%$, which is possible at high air injection rates. As an example, for $\alpha=0.31$ of compressed air injection, a rate of $0.05 \mathrm{~m}^{3} / \mathrm{s}$ yields maximum efficiency.

Figure 6 shows the correlation between the experimental efficiency and water lifting rate for mixer $\mathrm{P}_{1}$ at a submergence ratio of 0.7 . It is quite clear that the maximum efficiency of the pump does not belong to the time when we have the maximum rate of displaced water. This result emphasizes that increasing the amount of influent air cannot help much to enhance the airlift efficiency. Therefore, depending on the conditions of the mine, one can choose between the economic efficiency of pumping operation and draining water faster.

There are different opinions about the most effective submergence ratio for the optimum output of the airlift. Tighzert et al. (2013) concluded that the best performance of their 3 $\mathrm{m}$ long airlift was achieved at a submergence ratio of 0.75 , and that beyond that, the efficiency declines. Their recommended optimal range of submergence ratios for proper device performance was 0.4 to 0.75 , which is slightly different from our results. The discrepancy could be due to the dimension of our airlift and the pressure of the compressed air, which were both higher under their test conditions than in our study. We found that the optimum range of submergence ratios was from 0.6 to 0.75 . Outside this range, the performance of an airlift for two phase flow drops sharply and would likely be not economical.

Compared to other types of air jackets, the $\mathrm{P}_{1}$ type performed the best for vertical water transport with this airlift design (Fig. 7). $\mathrm{P}_{1}$ was much as $10 \%$ more efficient than types $\mathrm{P}_{2}$ and $\mathrm{P}_{3}$. The mixer $\mathrm{P}_{1}$ produced smaller and more regular air bubbles to enhance the delivery of water in the separator tank by creating more shear stress between the water molecules and the outer surface of air bubbles. Increasing the diameter of the holes in the airmixer reduces the efficiency of the pump; that is why the performance of $\mathrm{P}_{2}$ was better than $\mathrm{P}_{3}$. This condition was not always the same due to flow fluctuations and precision of the sensors, but in $90 \%$ of the cases, $\mathrm{P}_{2}$ provided better efficiency and maximum water flow rate compared to $\mathrm{P}_{3}$.

The results of our practical experiments show that to efficiently use an airlift pump for underground mine drainage, it is necessary to have a suitable height of water so that a submergence ratio of $0.6-0.75$ can be ensured. This in turn requires proper collection and delivery of water to the pumping site or finding a suitable place for a well in the aquifer. To give an illustration, if the water must be pumped $60 \mathrm{~m}$ above its static level, assuming an economic working condition $(\alpha=0.75)$, this requires a well with a minimum water depth of $180 \mathrm{~m}$. Providing such a situation creates its own problem in underground environments. 
Fig. 5 Pump efficiency and air flow rate at different submergence ratio for air-jacket $P_{1}$
Fig. 6 Water flow rate against air flow rate and efficiency for air-jacket $\mathrm{P}_{1}$ and $\alpha=0.7$
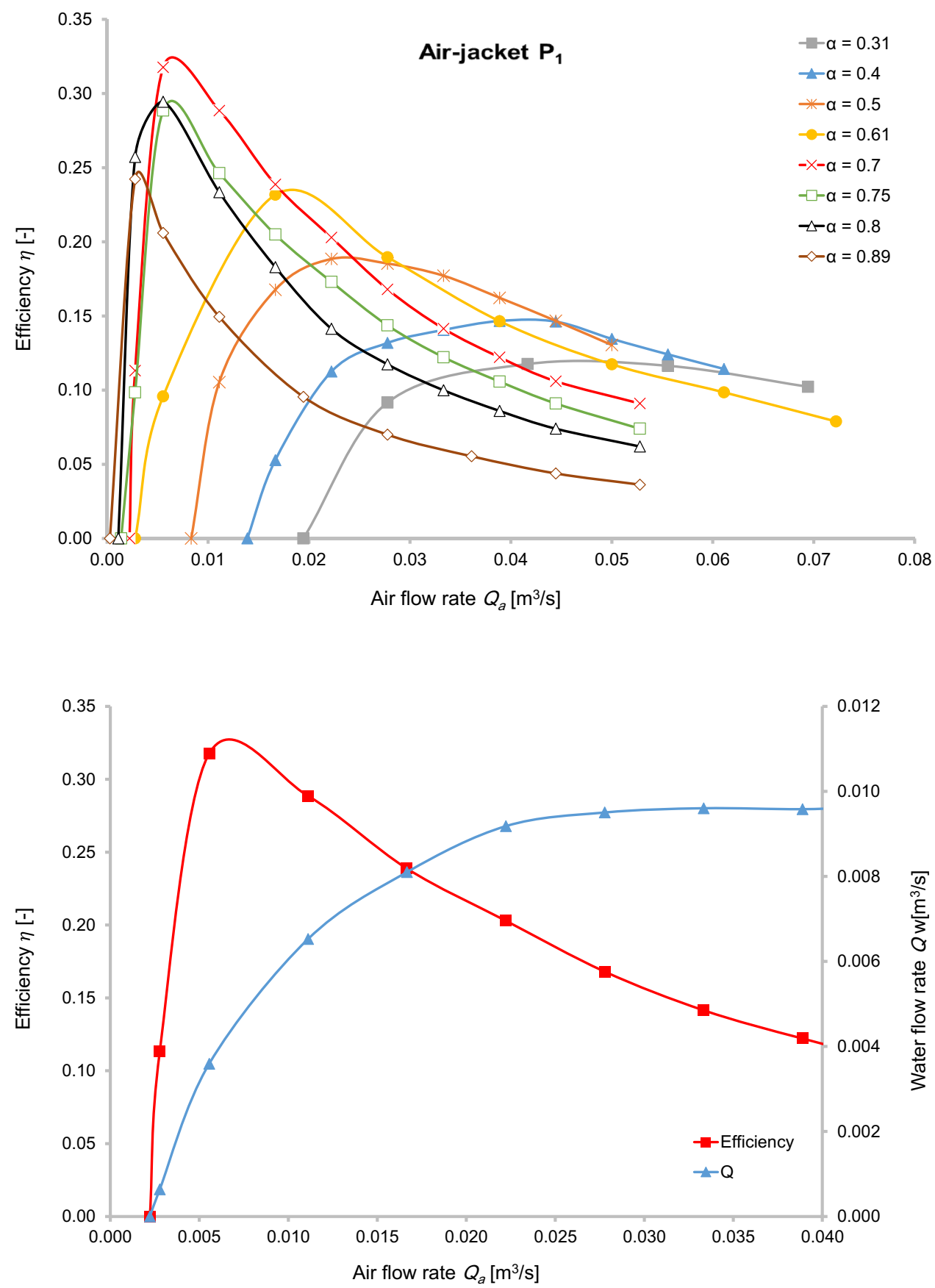

\section{Conclusion}

A preliminary design of an airlift pump using three type of air jackets and eight different submergence ratios, utilizing parallel injection of the compressed air into the manifold, was investigated experimentally. Based on the test results, the following main conclusions are drawn:
1- One of the effective parameters for airlift performance is to use an air jacket with smaller hole diameters. In terms of air consumption at a constant submergence ratio, the first type of air jacket $P_{1}$ with more of the smallest hole diameters $(3 \mathrm{~mm})$ required the least amount of air to start lifting water. Moreover, it was more efficient in pumping water than air jackets with bigger hole diameters $\left(\mathrm{P}_{2}\right.$ and $\left.\mathrm{P}_{3}\right)$.

2- Water flow fluctuations in the riser pipe reduce the efficiency of the airlift for vertical water transfer. To prevent 
Fig. 7 Lifting efficiency for three air-jackets at a submergence ratio of 0.31

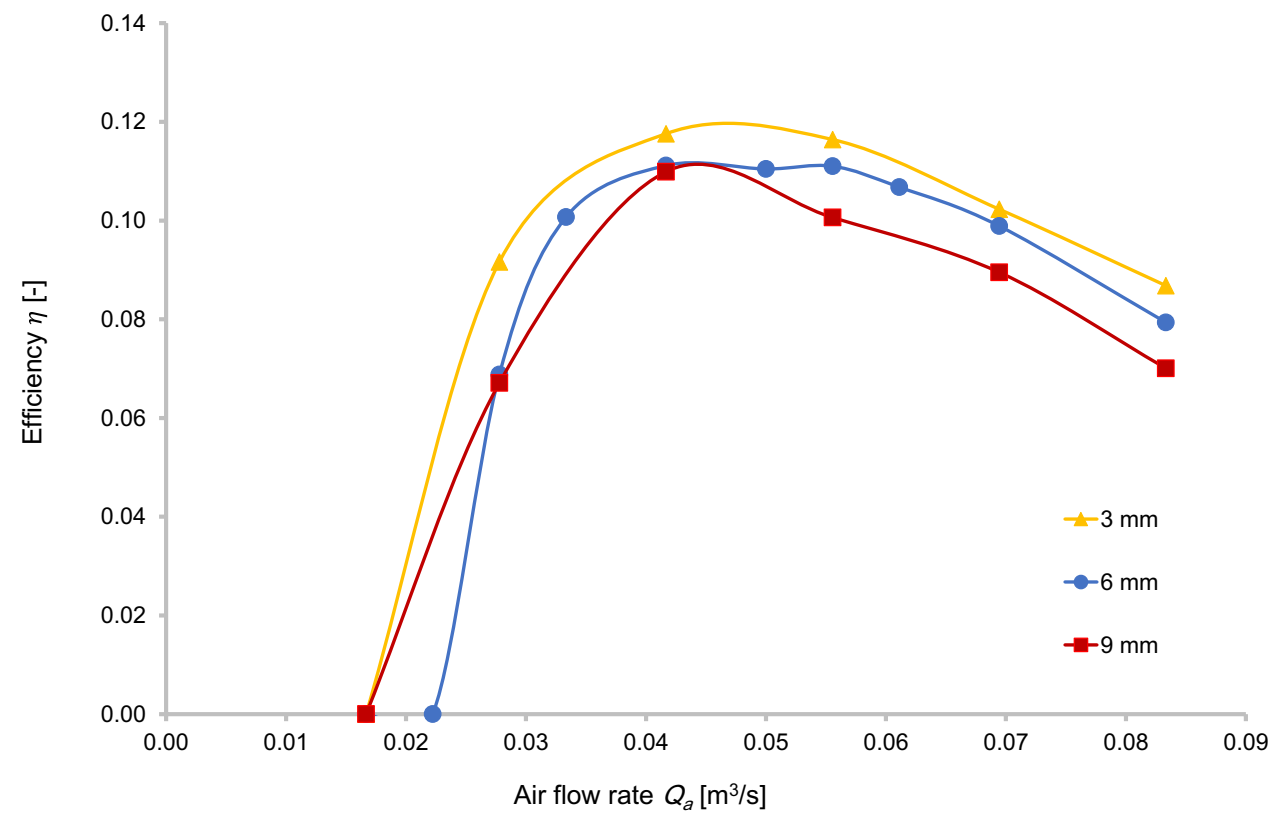

this phenomenon, it is necessary to correctly choose the amount of compressed air injection and the submergence ratio.

3- The amount of compressed air needed to have a continuous upward flow and maximum efficiency is different for each submergence ratio. However, the same trend exists for water pumping with an airlift. The water flow rate increases until an ultimate pumping rate is reached, beyond which the liquid flow rate remains constant despite increased air flow and finally decreases slightly.

4- According to the results, the maximum submergence ratio is equal to 0.75 , and beyond that, the efficiency of water pumping is reduced again, and only faster pumping rate can be achieved. The optimal submergence ratio for useful efficiency is between 0.6 and 0.75 if the compressed air is injected parallel into the manifold. However, the pumping height of water at submergence ratios above 0.6 is not significant. Thus, the airlift is more economical for pumping water at short altitudes above the static water level.

5- We found that neither of the two theoretical models (Hussain and Spedding 1976; Stenning and Martin 1968) compared well with our experimental results. To use these theoretical models to predict pumping performance with acceptable accuracy, it is necessary to modify them to estimate flow parameters for a wide range of pumping conditions with minimum deviations.

Supplementary Information The online version contains supplementary material available at https://doi.org/10.1007/s10230-021-00807-w.
Funding Open Access funding enabled and organized by Projekt DEAL. Funding was provided by European Research Council Grant number (800757).

Open Access This article is licensed under a Creative Commons Attribution 4.0 International License, which permits use, sharing, adaptation, distribution and reproduction in any medium or format, as long as you give appropriate credit to the original author(s) and the source, provide a link to the Creative Commons licence, and indicate if changes were made. The images or other third party material in this article are included in the article's Creative Commons licence, unless indicated otherwise in a credit line to the material. If material is not included in the article's Creative Commons licence and your intended use is not permitted by statutory regulation or exceeds the permitted use, you will need to obtain permission directly from the copyright holder. To view a copy of this licence, visit http://creativecommons.org/licenses/by/4.0/.

\section{References}

Abed R, Chadwick E, Ahmed W (2018) Two-phase flow behaviour in airlift pumps. Proceedings of the 5th International conference of fluid flow, heat and mass transfer (FFHMT'18), Niagara Falls, Canada - June 7 - 9, 2018, Paper No. 168. https://doi.org/10. 11159/ffhmt 18.168

Ahmed W, Aman A, Badr H, Al-Qutub A (2016) Air injection methods: the key to a better performance of airlift pumps. Exp Therm Fluid Sci 70(1):354-365

Awari G, Ardhapurkar P, Wakde D (2004) An experimental analysis of two phase flow for air lift pump design. Adv Fluid Mech (ISBN: 1-85312-704-3)

Cachard F, Delhaye J (1996) A slug-churn flow model for small-diameter airlift pumps. Int J Multiph Flow 22(4):627-649

Clark N, Dabolt R (1986) A general design equation for airlift pumps operating in slug flow. AIChE J 32(1):56-64

Francois O, Gilmore T, Pinto M, Gorelick S (1996) A physically based model for air-lift pumping. Water Resour Res 32:2383-2399 
Hussain L, Spedding P (1976) The theory of the gas-lift pump. Int J Multiph Flow 3:83-87

Jeelani S, Kasipati Rao K, Balasubramanian G (1979) The theory of the gas-lift pump: a rejoinder. Int J Multiph Flow 5(3):225-228

Kalenik M (2015) Investigations of hydraulic operating conditions of air lift pump with three types of air-water mixers. SGGW Land Reclam. https://doi.org/10.1515/sggw-2015-0015

Kassab S, Kandil H, Warda H, Ahmed W (2009) Air-lift pumps characteristics under two-phase flow conditions. Int J Heat Fluid Fl 30:88-98

Khalil M, Elshorbagy K (1979) Performance analysis of newly designed air lift riser. Proc Multiphase Transport Conf 4:1793-1806

Khalil M, Elshorbagy K, Kassab S, Fahmy R (1999) Effect of air injection method on the performance of an air lift pump. Int $\mathrm{J}$ Heat Fluid Fl 20:598-604

Ligus G, Zajac D, Masiukiewicz M, Anweiler S (2019) A new method of selecting the airlift pump optimum efficiency at low submergence ratios with the use of image analysis. Energies 12:735. https://doi.org/10.3390/en12040735

Liu L, Xiaobai L, Tong L, Liu Y (2014) Effect of surfactant additive on vertical two-phase flow. J Petrol Sci Eng 115:1-10

Lockhart R, Martinelli R (1949) Proposed correlation of data for isothermal two-phase, two-component flow in pipes. Chem Eng Prog 45:38-48

Maliky S (2014) Effect of suction pipe diameter and submergence ratio on air lift pumping rate. Adv Mater Res 1036:703-707

Neto I, Zhu D, Rajaratnam N (2008) Air injection in water with different nozzles. J Environ Eng 134(4):283-294. https://doi.org/10. 1061/(ASCE)0733-9372(2008)134:4(283)
Nicklin D (1963) The air-lift pump: theory and optimization. Trans Inst Chem Eng 41:29-39

Oueslati A, Megriche A (2017) The effect of liquid temperature on the performance of an airlift pump. Energy Proc 119:693-701

Parker G (1980) The effect of footpiece design on the performance of a small air lift pump. Int J Heat Fluid Fl 2:245-252

Pougatch K, Salcudean M (2008) Numerical modelling of deep sea air-lift. Ocean Eng 35:1173-1182

Reinemann D, Parlange J, Timmons M (1990) Theory of small-diameter airlift pumps. Int J Multiph Flow 16(1):113-122

Samaras V, Margaris D (2005) Two-phase flow regime maps for airlift pump vertical upward gas-liquid flow. Int J Multiph Flow 31:757-766

Sawiski J, Pawiowska A (1999) Energy balance for air lift pumps. Hydro-Eng Env Mech 46(1-4):63-72

Sharma ND, Sachdeva MM (1976) An air-lift pump performance study. AICHE J 32:61-64

Stenning A, Martin C (1968) An analytical and experimental study of air-lift pump performance. ASME J Eng Power 90:106-110

Taitel Y, Bornea D, Dukler AE (1980) Modelling flow pattern transitions for steady upward gas-liquid flow in vertical tubes. AlChE J 26(3):345-354

Tighzert M, Brahimi M, Kechroud N, Benabbas F (2013) Effect of submergence ratio on the liquid phase velocity, efficiency and void fraction in an air-lift pump. J Petrol Sci Eng 110:155-161

Weber M (1974) Fluid conveying technology. Krausskopf-verlag, pp 199-200 